Revista Brasileira de Cartografia

ISSN 1808-0936 | https://doi.org/10.14393/revbrascartogr

Sociedade Brasileira de Cartografia, Geodésia, Fotogrametria e Sensoriamento Remoto

\title{
Morfologia Urbana no Distrito De Ipiabas, Município de Barra do Piraí - Rio De Janeiro
}

\author{
Urban Morphology in the Ipiabas District, Municipality of Barra do Piraí - Rio De \\ Janeiro
}

Caio Flávio Martinez Fontoura Júnior ${ }^{1}$, Edmur Azevedo Pugliesi ${ }^{2}$ e Vilma Mayumi Tachibana ${ }^{3}$

1 Universidade Estadual Paulista - UNESP, Faculdade de Ciência e Tecnologia, Departamento de Cartográfica, Presidente Prudente SP, Brasil. E-mail: caio.fontoura@unesp.br.

ORCID: http://orcid.org/0000-0001-8948-351X

2 Universidade Estadual Paulista - UNESP, Faculdade de Ciência e Tecnologia, Departamento de Cartográfica, Presidente Prudente -

SP, Brasil. E-mail: edmur.pugliesi@unesp.br

ORCID: https://orcid.org/0000-0003-3426-6619

3 Universidade Estadual Paulista - UNESP, Faculdade de Ciência e Tecnologia, Departamento de Estatística, Presidente Prudente -

SP, Brasil. E-mail: vilma.tachibana@ unesp.br.

ORCID: http://orcid.org/0000-0002-8804-6163

Recebido: 08.2020 | Aceito: 10.2020

\begin{abstract}
Resumo: O processo de expansão urbana tem resultado em aglomerados populacionais desordenados, o que causa problemas para a administração municipal. A fim de mitigar este tipo de problema, uma das maneiras de reorganizar o território está no conceito de policentrismo. Nesse conceito, há duas abordagens que analisam esses problemas e que buscam soluções para eles, a funcional e a morfológica. No que diz respeito à análise pela abordagem morfológica, este trabalho de pesquisa objetivou a realização de análises que envolve renda, demografia e relevo, fatores que possam influenciar a estrutura da forma urbana do distrito de Ipiabas, um possível subcentro localizado no munícipio de Barra do Piraí, Rio de Janeiro. Para compreender a forma do distrito, as análises consistiram em: interpolar a localização das possíveis residências, representar a renda média per capta e a densidade demográfica, bem como modelar uma superfície que mostra classes de declividade. Os resultados mostram que a característica da forma urbana do distrito de Ipiabas está relacionada a topografia e que há predominância de assentamentos populacionais entre as encostas.

Palavras-chave: Centralidades Urbanas. Estimador de Densidade Kernel. Mapeamento Quantitativo. Declividade.
\end{abstract}

Abstract: The process of urban expansion has resulted in disorderly population clusters, which causes problems for the municipal administration. To mitigate this type of problem, one of the ways to reorganize the territory is in the concept of polycentrism. In this concept, there are two approaches to analyze these problems and seek solutions to them, the functional and the morphological. Concerning the morphological approach, this research work aimed the accomplishment of analyses involving income, demography, and relief, factors that may influence the structure of the urban form of Ipiabas district, a possible sub-center located in the municipality of Barra do Piraí, Rio de Janeiro. To understand the urban form, the analyzes consisted of : interpolating the location of possible residences, representing the average income per capita and the demographic density, as well as modeling a surface showing slope classes. The results show that the characteristic of the urban form of the Ipiabas district is related to topography and that there is a predominance of population settlements between the slopes.

Keywords: Urban Centralities. Kernel Density Estimator. Quantitative Mapping. Slope.

\section{INTRODUÇÃO}

A expansão da população urbana acompanhada de externalidades de várias aglomerações, tanto concentradas quanto dispersas, pode causar problemas para população e novos desafios para a administração pública municipal. Atualmente, o crescimento do tecido urbano da maioria das cidades se encontra em condições desordenadas. Na última década, especialistas buscaram encontrar estratégias que pudessem contribuir para a reorganização territorial, de modo que atendessem às necessidades do crescimento territorial urbano (ZHANG; SUN; LI, 2017). 
Há duas abordagens relevantes para interpretação e análise do policentrismo. Uma é a abordagem funcional e está relacionada com as redes de fluxos e a cooperação entre as regiões urbanas policêntricas (ESPON, 2011). Neste contexto, os principais atores de ligação ou comutação dentro da abordagem policêntrica estão relacionados com as cidades, pessoas, empresas, telefones e computadores (GREEN, 2007).

A outra é a abordagem morfológica, referente ao modo como as áreas urbanas estão distribuídas em uma determinada localidade (p.e.: número de cidades e hierarquia). A abordagem morfológica pode ser expressa como “...a pluralidade de centros urbanos em um determinado território. No entanto, a policentricidade tende está mais associada a uma distribuição equilibrada em relação à importância desses centros urbanos...” (BURGER; MEIJERS 2012, p. 1132, tradução nossa).

Devido às rápidas e contínuas mudanças territoriais contemporâneas, novos problemas e dificuldades sociourbanísticas têm surgido. Desse modo, são necessárias novas maneiras de operar, de pensar e de agir, especificamente nas cidades (FONSECA; RAMOS, 2004). Em consonância, Mafra e Silva (2004) afirmam que planejar o território requer novas tecnologias e sistemas de informações, o que torna essas ferramentas muito importantes na formulação e implementação de políticas públicas.

Nos últimos 15 anos surgiu uma ampla variedade de pesquisas, tendo como foco os conceitos do desenvolvimento do policentrismo (BURGER; MEIJERS, 2011). Dessa maneira, os pesquisadores buscam aplicar os estudos sobre o policentrismo em diversas escalas geográficas (local, regional e nacional) e com o emprego de diferentes metodologias (PARR, 2004; ESTUPIÑ́́N et. al, 2013; LI; LIU, 2018). Em relação à metodologia, os estudos foram aplicados com a utilização de Sistema de Informação Geográfica - SIG, modelos paramétricos, regressão linear e pela estatística descritiva espacial (MCDONALD; MCMILLEN, 1990; MCDONALD; PRATHER, 1994; LI; LIU, 2018).

A maioria desses estudos foi realizada em diversos países, com destaque para China, países da União Europeia e Estados Unidos. No Brasil, há poucos estudos sobre policentrismo ou polinucleação comparado aos países supracitados. No contexto nacional, as pesquisas que envolvem o policentrismo foram aplicadas com a utilização de abordagem funcional ou morfológica (WHITACKER, 2003; DA SILVA; SPOSITO, 2006; PESSOA, 2011; SALES, 2014; SILVEIRA et al., 2017; FERREIRA, 2018). Porém, há um fator importante para as localidades brasileiras, e que não é tão impactante nos países supracitados: a questão da topografia que pode ser um fator importante na compreensão de uma centralidade ou núcleo urbano.

Dessa maneira, o objetivo deste trabalho é estudar fatores que possam ter influência sob o aspecto morfológico no distrito de Ipiabas, um possível subcentro localizado no munícipio de Barra do Piraí - RJ. Este trabalho de pesquisa envolve questões de planejamento territorial e se enquadra no contexto do Estatuto da cidade, a lei $\mathrm{n}^{\circ} .10 .257$, de 10 de julho de 2001 (BRASIL, 2008).

\section{REVISÃO DE LITERATURA}

Os europeus foram os pioneiros a estabelecer um conceito de como reorganizar o território, que utilizou o planejamento espacial policêntrico (ZHANG; SUN; LI, 2017). O policentrismo surgiu na Europa por volta de 1930. Este modo de organização espacial e é baseado na Teoria do Lugar Central (TLC), o qual tem o objetivo de auxiliar o desenvolvimento regional para estabelecer uma estrutura urbana de modo que possa contribuir para a redução da disparidade entre diferentes localidades e proporcionar melhoraria da integração econômica, por meio do aumento da competitividade entre diferentes regiões (ESPON, 2011).

Conforme a TLC, os sistemas urbanos são, por definição, monocêntricos. O objetivo do monocentrismo está na importância da hierarquia entre regiões e não no equilíbrio, pois cada centralidade possui uma importância diferente em termos de centro, dentre os quais econômico, histórico, cultural, social e turístico (BURGER; MEIJERS, 2012). Transformar uma localidade monocêntrica em policêntrica pode ser uma maneira eficaz de reduzir aglomerações onde ocorrem há deseconomias (ZHANG; SUN; LI, 2017).

No modo de organização policêntrico há hierarquia entre os núcleos urbanos, em que as residências e variedade de bens podem ser consideradas perfeitamente correlacionadas (BURGER; MEIJERS, 2012). Desta maneira, os núcleos urbanos estão organizados em estrutura de pirâmide, dividida em três partes. Na base da pirâmide se encontram as regiões mais distantes do centro, chamado de interior; no meio da pirâmide se encontram os locais mais afastados do centro, porém próximos de algumas atividades econômicas, mas que 
não têm uma relação direta com a centralidade principal e; no topo está a centralidade principal, a qual exerce maior influência sobre as demais, devido à autossuficiência de oferecer uma ampla variedade de bens e serviços (BURGER; MEIJERS, 2012).

Há diversas interpretações sobre o policentrismo por diferentes autores, porém o fato que difere umas das outras é explicado pelo estudo em diferentes contextos e diferentes escalas geográficas. Contudo, o ponto comum do policentrismo é definido como uma área urbana composta de vários centros urbanos e que pode ser reconhecido também como polinucleação ou composição de vários subcentros. Neste contexto, o significado mais abrangente varia de acordo com o ponto de vista espacial, social, econômico e histórico (PESSOA, 2011).

Segundo Champion (2001), a escala geográfica parece ser uma das questões mais problemáticas no estudo do policentrismo, pois o grau de interação entre as localidades urbanas e a variedade de regiões contribuem para o surgimento de uma Região Urbana Policêntrica (Polycentric Urban Regions - PUR). Na literatura, é possível identificar pelo menos duas configurações policêntricas. Uma é a área metropolitana individual e a outra é a cidade como um todo. A cidade como um todo inclui os subúrbios e o deslocamento entre regiões, para áreas mais distantes. Por muitas vezes, a policentricidade ocorre devido às consequências das políticas e às mudanças sociais, as quais podem ter aspectos tanto positivos quanto negativos (GREEN, 2007).

A centralidade de uma região apresenta um intenso fluxo de atividades humanas, concentração de comércio e certa complexidade, tanto física quanto humana, que tornam essa região diferente das que se encontram em seu entorno, e essa variação ocorre de acordo com a cidade e depende de diversos fatores. Em uma mesma cidade podem existir diversos centros com uma grande concentração de comércios e prestação de serviços. Contudo, nem sempre a região central estará localizada na região geográfica de origem do centro do município, pois todo município tem uma centralidade onde se originou a cidade em uma determinada época, mas que hoje não se encontra mais nessa mesma região, devido aos fatores socioeconômicos (LOPES JÚNIOR; SANTOS, 2010).

\section{METODOLOGIA}

Para analisar a forma urbana no distrito de Ipiabas sob a influência da topografia, a metodologia foi organizada de acordo com as etapas presentes no fluxograma sumarizado apresentado na Figura 1. Anteriormente a estas etapas, foi feita a seleção da área de estudo. A etapa 1 consistiu na aquisição e tratamento dos dados. E, a etapa 2 consiste em aplicar a análise espacial pelo vizinho mais próximo médio, a Função $\mathrm{K}$ de Ripley para a determinação do raio de busca, o interpolador de densidade kernel para a geração da superfície de densidade de residências, e a geração da declividade.

Figura 1 - Etapas para a realização da análise morfológica.

Dados de entrada Processamento dos dados

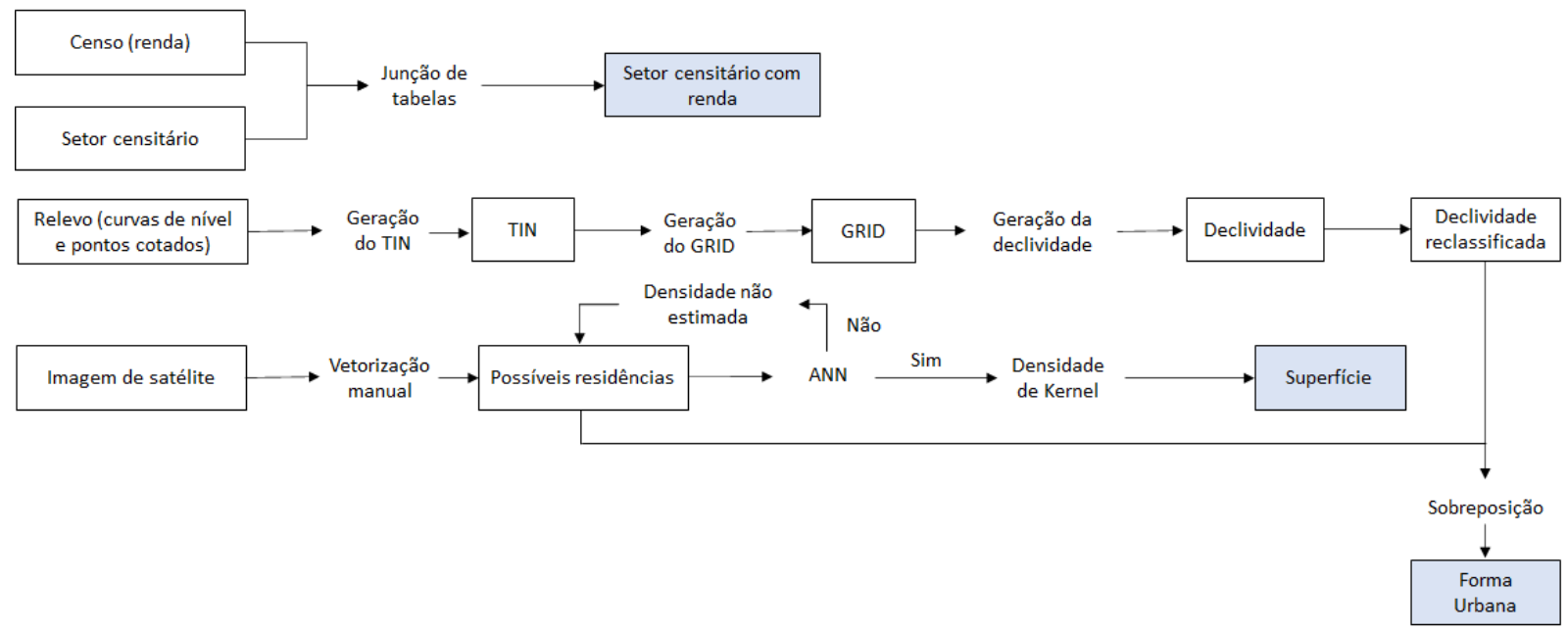

Fonte: Os autores (2021). 


\section{1 Área de Estudo}

Uma análise de policentrismo foi feita para o distrito de Ipiabas, o qual fica situado no munícipio de Barra do Piraí, na região Sul Fluminense do estado do Rio de Janeiro, Brasil. Foi utilizada a abordagem morfológica para identificar micronúcleos na região local. O distrito possui área aproximada de $44.365 \mathrm{Km}^{2}$ e, segundo o censo do Instituto Brasileiro de Geografia e Estatística (IBGE) de 2010, cerca de 3.954 habitantes, sendo este um dos seis distritos do município de Barra de Piraí (IBGE, 2018). Á área de estudo está estabelecida entre as latitudes de $22^{\circ} 21^{\prime \prime} \mathrm{S}$ e $23^{\circ} 24^{\prime \prime} \mathrm{S}$, e longitude $43^{\circ} 51^{\prime \prime} \mathrm{O}$ e $44^{\circ} 53^{\prime \prime} 30^{\prime} \mathrm{O}$ (Figura 2).

Ipiabas é a quarta divisão administrativa de Barra do Piraí e está localizada a 16,6 km do centro principal do município, sendo o mais próximo da sede. O distrito se encontra a uma altitude média de 750 metros, possui clima temperado e o local contribui para atrair turistas nesta região (PREFEITURA DE BARRA DO PIRAÍ, 2015). Existem diversas trilhas ecológicas e cachoeiras, e costuma receber eventos importantes como o circuito do Vale do Café, o que o torna principal polo turístico do munícipio de Barra do Piraí, RJ.

Figura 2 - Mapa de localização de Ipiabas, distrito de Barra do Piraí, RJ.
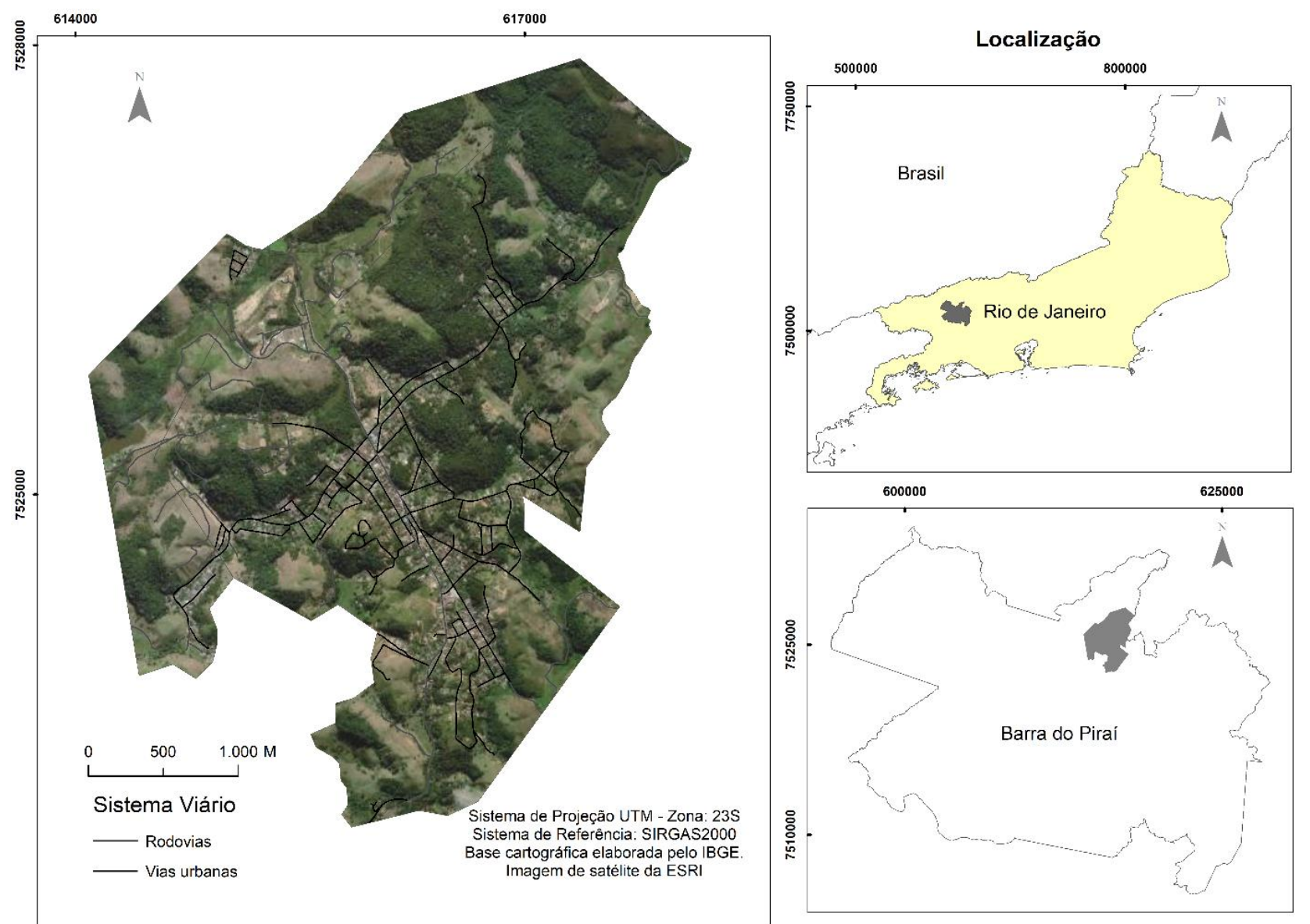

Fonte: Os autores (2021).

\subsection{Aquisição e tratamento dos dados}

Os dados utilizados neste trabalho foram: base cartográfica de setor censitário de 2010 do IBGE; base cartográfica de sistema viário e relevo, em escala 1:25.000 do ano de 2018; e imagem de satélite de 2013 da Environmental Systems Research Institute (ESRI). Os dados sobre a população e rendimento médio são provenientes do censo demográfico de 2010, e os dados de residências foram obtidos de imagens de satélites que datam de 2013.

Foi realizado um recorte espacial na base cartográfica do município de Barra do Piraí para analisar a forma urbana somente do distrito de Ipiabas. Os dados vetoriais utilizados nesse processamento consistiram em: curvas de nível e pontos cotados, vias urbanas e vias rurais. A base cartográfica estava em sistema de referência WGS84, o qual foi transformado para o SIRGAS2000 por meio do software ArcGIS. A etapa de 
preparação dos dados resultou em uma base com Projeção conforme de Gauss-Krüger (UTM - Universal Transversa de Mercator), zona 23, hemisfério Sul.

Os dados socioeconômicos do censo demográfico de 2010 estavam armazenados na base cartográfica com geometria de polígono. Esses dados alfanuméricos, armazenados nos polígonos que representam os setores censitários, não permitiam determinar a localização geográfica onde as pessoas residem. Para minimizar a representação da população em locais onde não há residências, utilizou-se a imagem de satélite disponibilizada no modulo BaseMap, do ArcGIS, desenvolvido pela empresa ESRI. Esta imagen do BaseMap é a mesma utilizada no Bing Maps. A imagem de satélite da ESRI está disponível para acesso e utilização gratuita no software QGIS. A partir disso, foi feita a vetorização de dados pontuais em uma camada que corresponde à localização das construções. Isto aconteceu por vetorização manual sobre a imagem. Cada ponto representa uma construção, considerada neste trabalho uma possível residência. Além disso, realizou-se um trabalho de campo, uma observação in locu, para realizar a análise dos resultados.

\subsection{Análises dos dados}

Para identificar em quais setores censitários residem os habitantes com os maiores e os menores salários mínimos (SM) no distrito de Ipiabas, foi feita a união de tabelas alfanuméricas com os polígonos dos setores censitários. Posteriormente, os dados contidos nos polígonos dos setores censitários foram copiados para os pontos, os quais representam os locais das possíveis residências. Dessa maneira, foi possível estimar a média de pessoas por residência, visto que se conhecia a quantidade total de habitantes por setor censitário e a quantidade de possíveis residências.

Com o intuito de identificar o padrão espacial das possíveis residências, foi aplicada a função do vizinho mais próximo médio (Average Nearest Neighbor - ANN). O índice resultante do processamento revela o tipo de padrão espacial e permite seguir com a análise de densidade caso o valor encontrado indique a presença de aglomerados. Segundo Whallon (1974), a função do vizinho mais próximo médio é calcular um índice com base na distância média das distâncias mínimas de cada feição até a feição vizinha mais próxima. Se o índice for menor que 1,0 (um) pode-se afirmar que há padrões de aglomerados e se o índice for maior que 1,0 (um) pode-se afirmar que há dispersão.

Para estimar o raio de busca a ser utilizado no estimador de densidade Kernel foi necessário aplicar a Função K de Ripley. Em seguida, foi aplicado o método de interpolação kernel com a utilização das feições pontuais que compreendem as possíveis residências. Foi utilizada a função Kernel Quártico. O objetivo dessa operação é analisar os locais de maior densidade de residências que podem indicar a presença de subcentralidade ou micronúcleos no distrito. A Eq. (1) representa a formulação geral do interpolador kernel (SILVERMAN, 1986).

$$
\text { Densidade }=\frac{1}{\left(\text { raio }^{2}\right.} \sum_{i=1}^{n}\left[\frac{3}{\pi} * \operatorname{pop}_{i}\left(1-\left(\frac{\text { dist }_{i}}{\text { raio }^{2}}\right)^{2}\right)^{2}\right]
$$

Na equação, o $i=1, \ldots, 0$ são os pontos de entrada; o op $_{i}$ é o campo populacional do ponto $\mathrm{i}$, no qual é um parâmetro opcional; e, o dist ${ }_{i}$ é a distância entre o ponto i e a localização (x, y) (SILVERMAN, 1986).

Segundo Câmara e Carvalho (2004), o interpolador kernel é aplicado em pontos identificados no espaço, tais como a localização de crimes, demografia e ocorrência de doenças, com o intuito de compreender a maneira como os dados estão distribuídos no espaço, se aleatória, dispersa ou aglomerada. Desse modo, a função enfatiza a maior importância para a localização espacial do evento.

Para apoiar a verificação da influência da topografia na forma urbana do distrito de Ipiabas, foi gerado um Modelo Digital de Terreno (MDT) da área de estudo gerado a partir de curvas de nível e pontos cotados. Posteriormente, foi gerado uma camada de declividade, por meio da interpolação de Delaunay.

Na literatura que trata de ocupação do solo para fins de loteamentos urbanos há recomendações sobre as declividades que são apropriadas para diferentes fins, conforme pode ser observado no Quadro 1 (CASTELLO, 2008). Dessa maneira, foi decidido gerar um mapa de declividade reclassificado que evidencia duas classes, uma até $30 \%$ e outra acima de $30 \%$. 
Quadro 1 - Declividades apropriadas para urbanização.

\begin{tabular}{|l|l|}
\hline Intervalos & Aspectos \\
\hline $0 \%$ até $8 \%$ & Compatível com via arterial \\
\hline $8 \%$ até $10 \%$ & Compatível com via coletora \\
\hline $10 \%$ até $12 \%$ & Compatível com via local \\
\hline $12 \%$ até $30 \%$ & Compatível com área urbanizável \\
\hline Acima de $30 \%$ & Incompatível com urbanização \\
\hline
\end{tabular}

Fonte: Adaptado de Castello (2008).

\section{RESULTADOS E DISCUSSÃO}

A distribuição espacial dos habitantes em relação ao rendimento médio foi feita a partir da junção dos dados de rendimento médio e setores censitários, como mostra a Figura 3(a). A partir dessa análise, foi possível identificar as regiões que se localiza a porção da população de maior e menor poder aquisitivo. Os dados do IBGE foram classificados em cinco classes: habitantes que recebem até $1 \mathrm{SM}(\leq 1 \mathrm{SM})$, habitantes que recebem mais de $1 \mathrm{SM}$ até $2 \mathrm{SM}(1<\mathrm{SM} \leq 2)$, habitantes que recebem mais de $2 \mathrm{SM}$ até $3 \mathrm{SM}(2<\mathrm{SM} \leq 3)$, habitantes que recebem mais de $3 \mathrm{SM}$ até $5 \mathrm{SM}(3<\mathrm{SM} \leq 5)$ e habitantes que recebem mais de $5 \mathrm{SM}$ até $10 \mathrm{SM}(5<\mathrm{SM} \leq$ 10). Parte da população que tem renda média de até 1 SM está distribuída ao longo de todo o distrito. Por outro lado, a maior parte da população que recebe mais de $5 \mathrm{SM}$ até $10 \mathrm{SM}$ (maior renda) está localizada na porção nordeste e na porção leste do distrito. Vale destacar que a região central do distrito (setor censitário 7), apresenta somente dois intervalos de rendas (até $1 \mathrm{SM}$ e de $1 \mathrm{SM}$ até $2 \mathrm{SM}$ ). Isto pode ser explicado pelo fato de o distrito ter sido expandido a partir dessa região, onde se encontra uma antiga estação férrea, atualmente desativada. O mapa apresentado na Figura 3(b) mostra os dados que se encontram na Tabela 1, correspondentes à distribuição espacial da população.

Figura 3 - Rendimento médio dos habitantes do distrito de Ipiabas (a); número de possíveis residências e do número de pessoas por setor (b).
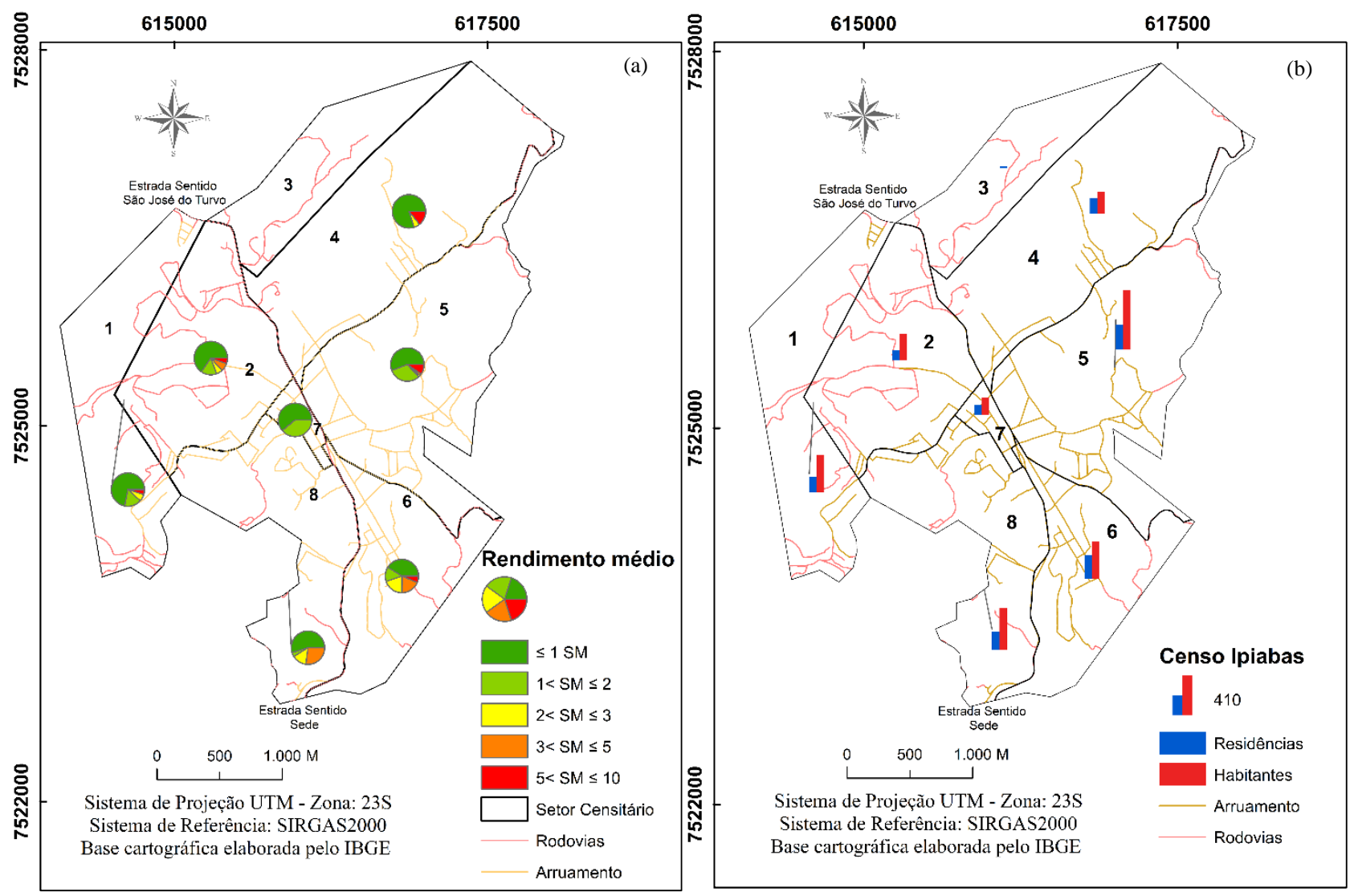

Fonte: Os autores (2021).

Para estimar uma aproximação para o número de habitantes que se encontra em cada setor censitário, utilizou-se os dados do processo manual de identificação dos pontos das possíveis residências (Tabela 1). Além disso, a partir dos cálculos realizados, o número de pessoas por residências foi estimado. 
Tabela 1 - Número de residentes por setor censitário.

\begin{tabular}{ccccc}
\hline $\begin{array}{c}\text { Setor } \\
\text { censitário }\end{array}$ & $\begin{array}{c}\text { Números de } \\
\text { habitantes estimados }\end{array}$ & $\begin{array}{c}\text { Números de } \\
\text { residências }\end{array}$ & $\begin{array}{c}\text { Razão entre o número de habitantes } \\
\text { e o número de residências }\end{array}$ & $\begin{array}{c}\text { Habitantes que recebem mais } \\
\text { de 5 SM até 10 SM }(\%)\end{array}$ \\
\hline 1 & 517 & 210 & 2,46 & 4,83 \\
\hline 2 & 367 & 139 & 2,64 & 5,44 \\
\hline 3 & 0 & 20 & 0 & 0 \\
\hline 4 & 301 & 208 & 1,44 & 12,96 \\
\hline 5 & 828 & 343 & 2,41 & 9,18 \\
\hline 6 & 515 & 323 & 1,59 & 6,21 \\
\hline 7 & 238 & 143 & 1,66 & 0 \\
\hline 8 & 592 & 262 & 2,26 & 0
\end{tabular}

O número de habitantes para o setor 3 é igual a zero. Esta incompatibilidade com o número de residências adquiridas sobre a imagem de satélite proveniente do Basemap, com a data 2013, pode ser justificada pelo fato da coleta do censo ter ocorrido em 2010. Os setores em que a quantidade de habitantes é bem maior do que a quantidade de residências representam o número de pessoas que recebem entre 1 e 5 salários, enquanto o setor censitário de número 5 representa o que tem maior número de residências. $\mathrm{O}$ setor 4 apresenta uma quantidade de habitantes próxima ao número de residências que recebem mais de $5 \mathrm{SM}$ e 10 SM.

O resultado do processo de vetorização de dados pontuais utilizado para estabelecer uma camada geográfica com a localização das possíveis residências é apresentado na Figura 4. A grande maioria das residências localizadas em Ipiabas está concentrada ao longo dessas vias arterial, coletora e local. Adicionalmente, a representação cartográfica permitiu compreender que há diversas residências distantes dessas vias.

Figura 4 - Distribuição dos pontos como possíveis residências no distrito de Ipiabas.

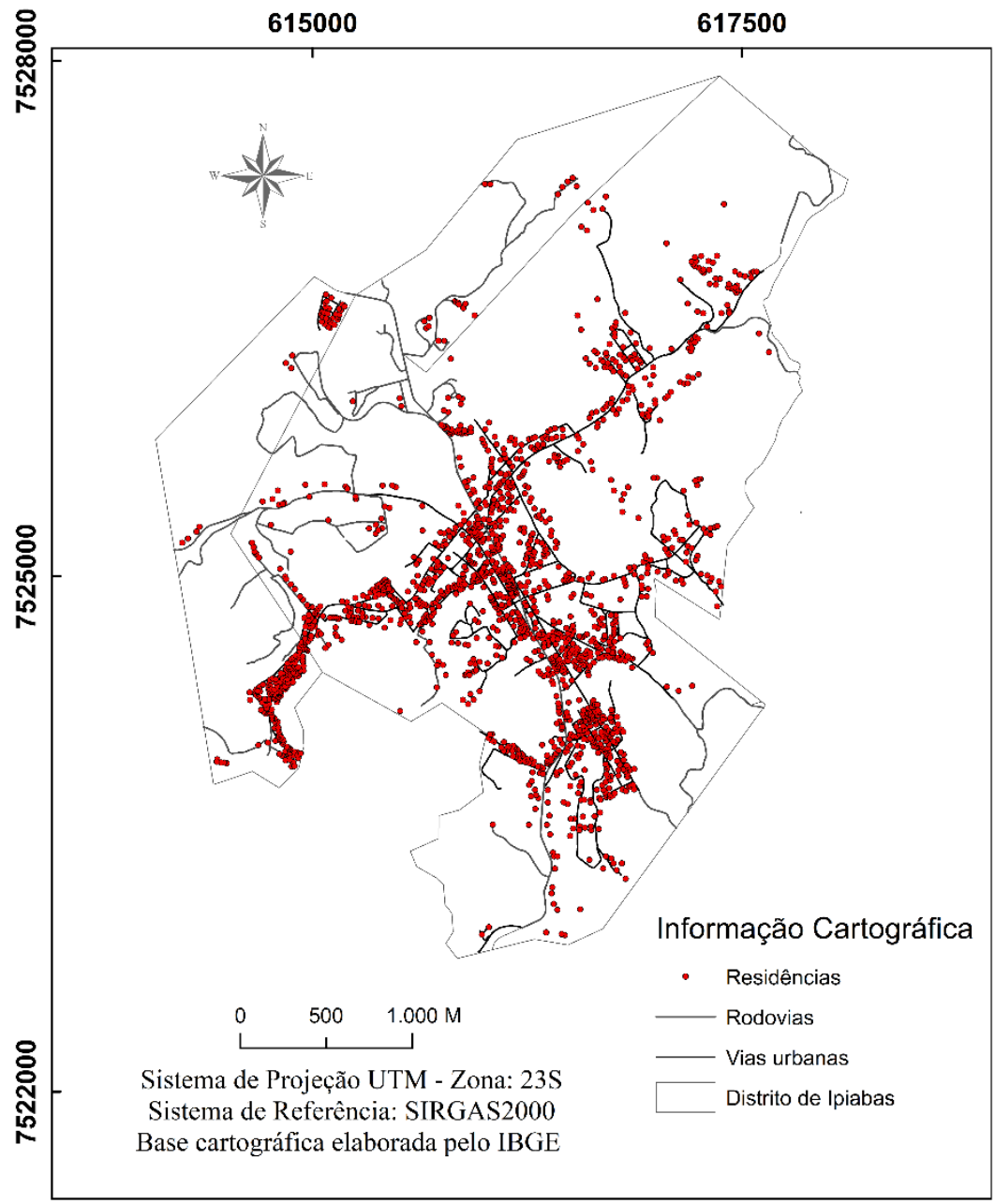

Fonte: Os autores (2021). 
A aplicação da função do vizinho mais próximo médio resultou em um índice igual a 0,5 (Z-score = 38,22 ; e p-valor $=0,0000001$ ). Este valor indica a presença de um padrão aglomerado para possíveis residências. Em seguida, o gráfico resultante da aplicação da Função K (Figura 5) mostra que o aglomerado de possíveis residências acontece entre 100 e 1.100 metros, com valores estatisticamente significativos. A partir disso, decidiu-se utilizar o raio de 150 metros para gerar a superfície de densidade kernel, de modo que o resultado enfatiza as áreas com maiores concentrações.

Figura 5 - Função K de Ripley para as possíveis residências de Ipiabas.

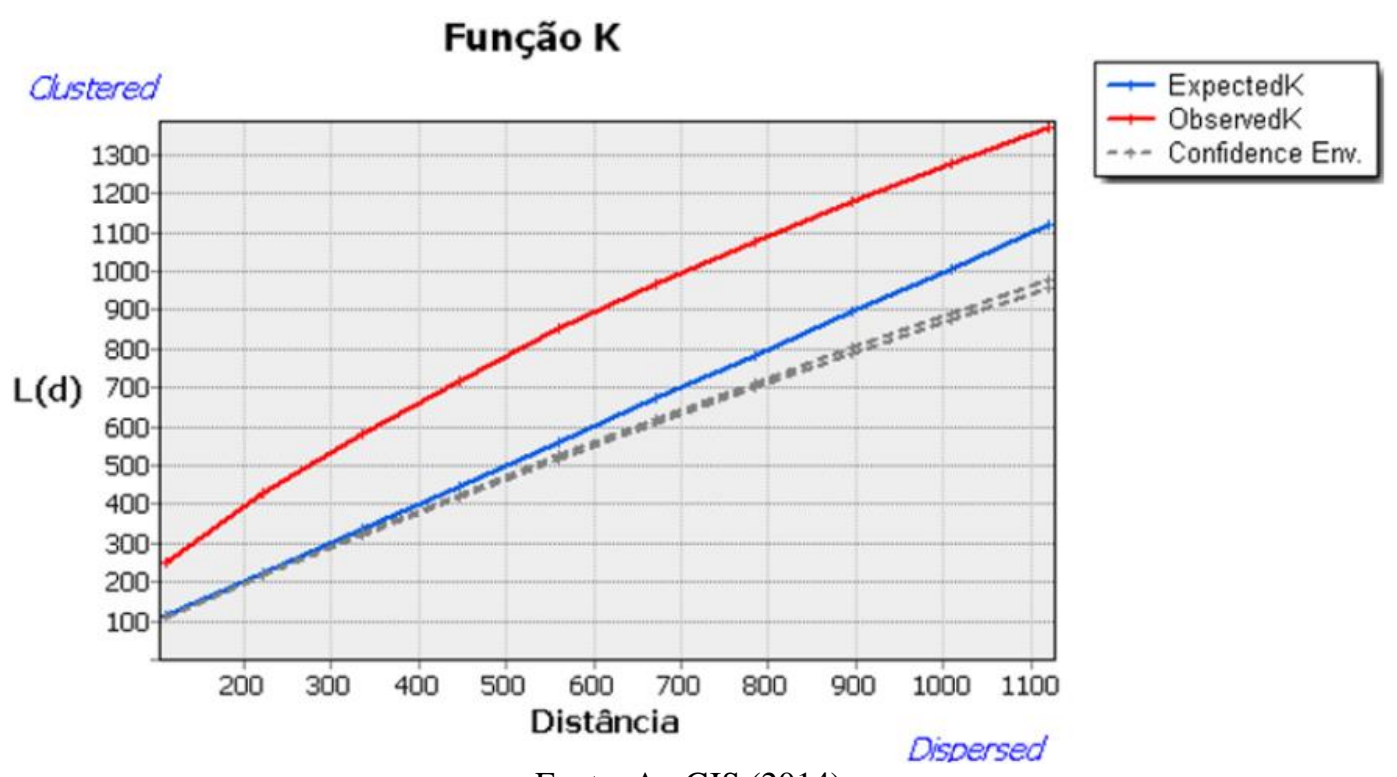

Fonte: ArcGIS (2014).

A aplicação do interpolador de densidade kernel resultou em uma superfície contínua que representa a densidade da distribuição das possíveis residências na área de estudo. A Figura 6(a) indica onde se localizam as concentrações e os picos populacionais dentro do distrito. Estes picos de concentração se encontram ao longo das vias, na parte sudeste, na entrada do distrito, e mais ao sudoeste devido ao fato da estrada se encontrar no meio da cidade. A porção sudoeste tem uma grande concentração de habitantes pelo fato de ter alguns hotéis, pousadas e pontos turístico nessa localidade. Além disso, há o fator da declividade que tem apresentado influência nessa concentração, pois os habitantes vão se acomodando no território pela disponibilidade de terrenos para a construção de residências. Na parte sudeste, pode ser explicado pelo fato de que essa região está situada entre a região central e a sede do município, fazendo com que os habitantes escolham essa região. Além disso, a declividade também apresentou influência para que essa porção tivesse maior quantidade de habitantes.

A sobreposição visual dos locais de residências com as classes de declividade compatível com área urbanizável (até 30\%) e incompatível com área urbanizável (acima de 30\%) mostra que a população vem se assentando entre as encostas (Figura 6(b)). O mapa de declividade destaca duas classes, de modo que possa auxiliar na identificação das residências que estão dentro ou fora da declividade permitida no distrito de Ipiabas. 
Figura 6 - Densidade populacional estimada pelo interpolador kernel (a); Distribuição das residências em função da

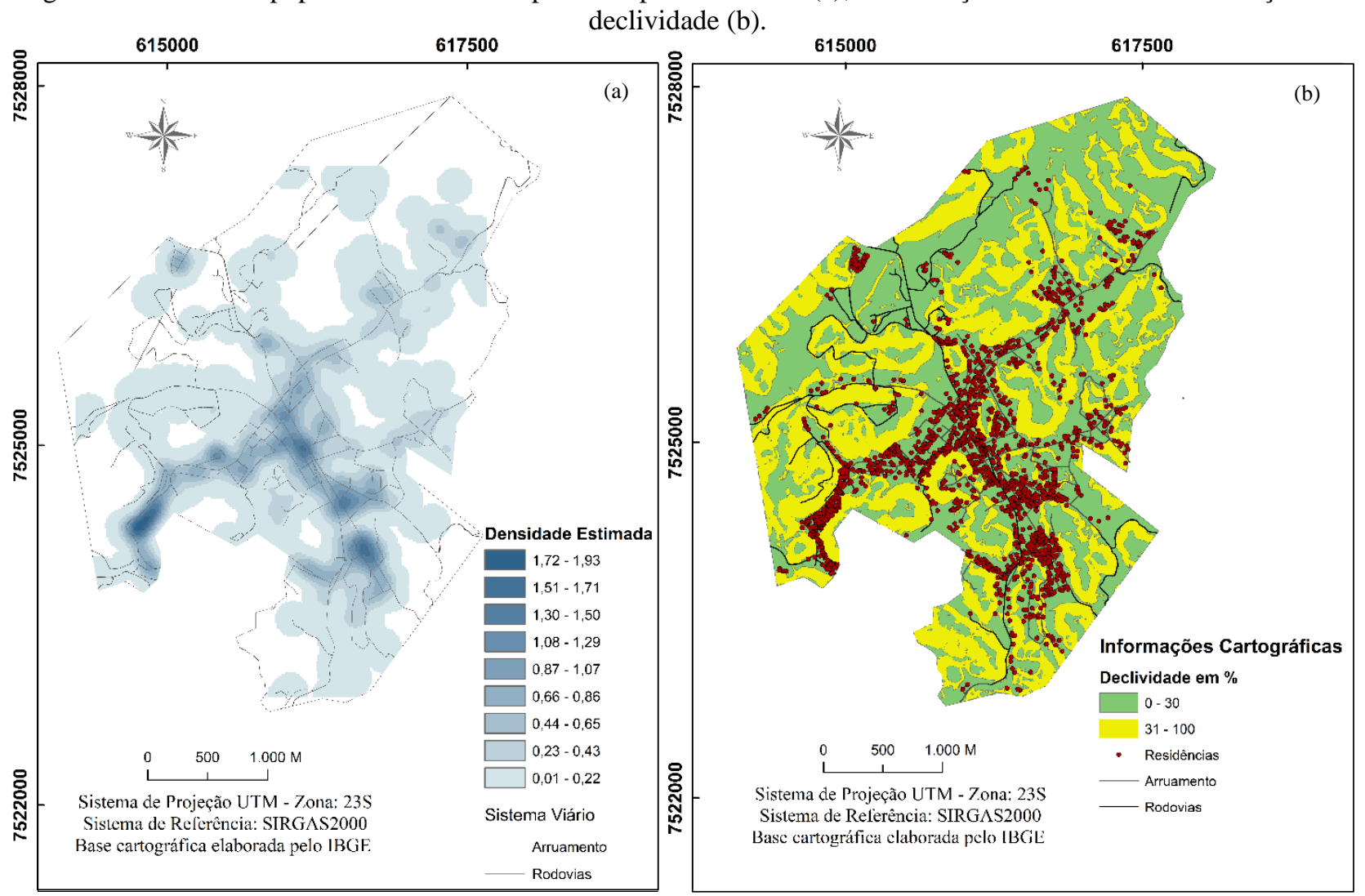

Fonte: Os autores (2021).

A declividade mostrou influência na organização da estrutura urbana do distrito. O mapa de declividade reclassificado com duas classes, uma até $30 \%$ e outra acima de $30 \%$, possibilitou a visualização das áreas permitidas e das áreas não permitidas. Foi possível identificar que a maior parte das residências se encontram em regiões permitidas, isto é, há um maior número de residências inseridas em locais com declividade menor que $30 \%$. Cerca de $11,34 \%$ das residências se localizam em áreas com declividade acima de $30 \%$, ou seja, em áreas não permitidas segundo apresentado por (CASTELLO, 2008). Vale ressaltar que esses resultados com dados altimétricos foram obtidos de uma base cartográfica na escala 1:25.000.

\section{CONSIDERAÇÕES FINAIS}

A análise da morfologia urbana pode requer a investigação de diversos fatores. Dentre aqueles analisados neste trabalho, alguns apresentaram maior influência do que outros. As análises de estimar a densidade e a declividade apresentaram maior influência na forma urbana do que as análises baseadas nos fatores econômicos. De qualquer modo, os dados econômicos oriundos da base de setores censitários de 2010 e da declividade calculada, foi possível identificar que parte da população com renda média mais de 5 SM até 10 salários mínimos (SM) se localiza em regiões com topografia irregular.

A distribuição das residências no espaço, representadas no mapa de pontos distribuídos geograficamente, auxiliou no comportamento espacial das residências, mas não foi suficiente para determinar os núcleos de maior densidade. Com isto, a análise de eventos pontuais, com o estimador de densidade, permitiu a identificação das subáreas mais densamente construídas dentro do distrito. A análise de declividade possibilitou identificar se as residências se encontram em locais com declividade permitida ou não.

A análise de dados a partir de setores censitários não permitiu identificar o número de residências que há em um cada setor censitário. Por isto, os resultados das análises espaciais elencadas neste trabalho são provenientes da utilização de dados com diferentes épocas, sendo os dados do censo coletados em 2010 e a imagem de satélite tomada em 2013. Apesar de haver essa diferença, os resultados se expressam de modo relevante para constituir uma metodologia de análise.

A metodologia utilizada neste trabalho de pesquisa pode ser adaptada e aprimorada para a realização 
de trabalhos futuros, para locais que tenham a presença de áreas com declividade acentuada. Desde modo, novos trabalhos que envolvem análises de densidade combinadas com a declividade podem ser realizados para escala de município. As limitações que este estudo apresenta são: a data da imagem de satélite usada para coletar as possíveis residências foi diferente da data dos dados do censo; as análises foram aplicadas em um núcleo sem interação com os demais distritos e a sede que se encontram no município. Dessa forma sugere-se que novos trabalhos possam considerar esses fatores para alcançar dados com maior qualidade.

\section{Agradecimentos}

Os autores agradecem ao Programa de Pós-graduação em Ciências Cartográficas - PPGCC, à Escola Nacional de Ciências Estatísticas (ENCE) pelo fornecimento dos dados, e à Coordenação de Aperfeiçoamento de Pessoal de Nível Superior Brasil (CAPES) - Código de Financiamento 001.

\section{Contribuição dos Autores}

O presente artigo culminou de estudos realizados durante o curso de mestrado do autor C. F. M. F. J. O professor E. A. P. foi o orientador e a professora V. M. T. foi a coorientadora. O estado da arte, tratamento e processamento dos dados, análise dos dados e elaboração da redação do texto foram realizadas por C. F. M. F. J. A revisão da redação e das análises espaciais foram realizadas por E. A. P. A análise estatística foi realizada por V. M. T.

\section{Conflitos de Interesse}

Os autores declaram que não há conflitos de interesse.

\section{Referências}

ARCGIS. ArcGIS: Software. 2014. Versão 10.3. ESRI, Redlands, Califórnia, EUA. Disponível em: <http://www.esri.com/software/arcgis/index.html>. Acesso em: 06 mar. 2018.

BURGER, M.; MEIJERS, E. Form Follows Function? Linking Morphological and Functional Polycentricity. Urban Studies, v. 49, n.5, p. 1127-1149, 2012. DOI: 10.1177/0042098011407095

BRASIL. Lei no ${ }^{\circ} 10.257$ de 10 DE JULHO DE 2001. Estatuto da cidade. Senado Federal, Brasília, DF, p.1102, 2008.

CÂMARA, G; CARVAlho, M. S. Análise de Eventos Pontuais. In DRUCK, S.; CARVALHO, M. S.; CÂMARA, G.; MONTEIRO, A. M. V. Análise Espacial de Dados Geográficos. Brasília: EMBRAPA, 2004. p. 57-72.

CASTELLO, I. R. Bairros, loteamentos e condomínios: Elementos para o projeto de novos territórios habitacionais. $1^{\text {a }}$ ed. Porto Alegre: UFRGS, 2008.

CHAMPION, A. G. A Changing Demographic Regime and Evolving Polycentric Urban Regions: Consequences for the Size, Composition and Distribution of City Populations. Urban Studies, v. 38, n. 4, p. 657-677, 2001. DOI: 10.1080/00420980120035277

DA SILVA, W. R.; SPOSITO, M. E. B. Padrões socioeconômicos e centralidade urbana: Catuai Shopping Center e zona norte de Londrina. Revista Formação (Online), v. 2, n. 10, 2006, p. 197-221. DOI: 10.33081/formacao.v2i13.622

ESPON. European Observation Network for Territorial Development and Cohesion. ESPON 111 Potentials for polycentric development in Europe. Project report 2011. Disponível em: < https://www.espon.eu/sites/default/files/attachments/fr-1.1.1_revised-full_0.pdf >. Acesso em: 09 set. 2019.

ESTUPIÑÁN, N. R.; DUARTE, C. MARMOLEJO; FERNÁNDEZ, M. T. Measuring Functional 
Polycentricity for the Analysis of Structural Places: The Case of the Seven Principal Metropolitan Areas in Spain. 53rd Congress of the European Regional Science Association: "Regional Integration: Europe, the Mediterranean and the World Economy", 2013. p. 1-22.

FERREIRA, H. M. Análise Crítica da Noção de Policentrismo: Uma Contribuição ao Estudo da Centralidade em Cidades Médias. GEOgraphia, v. 20, n. 44, p. 98-112, 2018. DOI: /10.22409/GEOgraphia2018.v1i44.a14406

FONSECA, F. P.; RAMOS, R. A. R. O Planejamento Estratégico na busca de potenciar o território. XI Jornadas da Associação dos Urbanistas Portugueses Territórios e Desenvolvimento. Santa Maria da Feira, 2004. p. 1-11

GREEN, N. Functional Polycentricity: A Formal Definition in Terms of Social Network Analysis. Urban Studies, v. 44, n. 11, p. 2077-2103, 2007. DOI: 10.1080/00420980701518941

IBGE - INSTITUTO BRASILEIRO DE GEOGRAFIA E ESTATÍSTICA. 2010. Site <https://cidades.ibge.gov.br/brasil/rj/barra-do-pirai/panorama>. Acesso em: 15 dez. 2018.

LI, Y.; LIU, X. How did urban polycentricity and dispersion affect economic productivity? A case study of 306 Chinese cities. Landscape and Urban Planning, v.173, 2018, p. 51-59. DOI: 10.1016/j.landurbplan.2018.01.007

LOPES JÚNIOR, W. M.; SANTOS, R. C. B. Reprodução do Espaço Urbano e a Discussão de Novas Centralidades. Revista Raega, n. 19, p. 107-123, 2010. DOI: http://dx.doi.org/10.5380/raega.v19i0.14827

MAFRA, F.; SILVA. J. A. Planeamento e Gestão do Território. Porto-PT: Sociedade Portuguesa de Inovação (SPI). 2004.

MCDONALD, J. F. y MCMILLEN, D. P. Employment subcenters and land values in a polycentric urban area: the case of Barcelona. Environment and Planning A, n. 22, 1990, p. 1561-1574. DOI: 10.1068/a221561

MCDONALD, J. y PRATHER, P. Suburban employment centres: The case of Chicago, Urban Studies, n. 31, 1994, p. 201-218. DOI: 10.1080/00420989420080201

PARR, J. “The Polycentric Urban Region A Closer Inspection”, Regional Studies, v. 38, n. 3, 2004, p. 231 240. DOI: $10.1080 / 003434042000211114$

PESSOA, R. P. P. Em Busca de uma Definição de Policentrismo Urbano para as Metrópoles Brasileiras. Revista Paranaense de Desenvolvimento, n. 120, 2011. p.297-318.

PREFEITURA DE BARRA DO PIRAÍ. Ipiabas. 2015. Disponível em: <http://barradopirai.rj.gov.br/portal /index.php?option=com_content\&view=article\&id=125\&Itemid=251>. Acesso em: 10 fev. 2019.

SALES, A. L. P. Situação Espacial de Franquias na América do Sul: morfologia e centralidade urbanas em cidades médias da Argentina, Brasil e Chile. 2014. 254 f. Tese (Doutorado em Geografia) - Universidade Estadual Paulista, Faculdade de Ciências e Tecnologia, Presidente Prudente, 2014.

SILVEIRA, R. L. L.; BRANDT, G. B. FACCIN, C. R.; SILVEIRA, L. L.; KUMMER, D. C. Policentrismo, Áreas Urbanas Funcionais (FUAs) e Dinâmica Territorial: Um estudo exploratório desde a região do Vale do Rio Pardo - RS - Brasil. Redes, v. 22, n. 1, 2017. p. 184-217. DOI: 10.17058/redes.v22i1.8641

SILVERMAN, B. W. Density estimation for statistics and data analysis. 1 ed. Inglaterra: Springer-Science + Business Media, B.Y., 1986. 183p.

WHALLON, Robert. Spatial analysis of occupation floors II: the application of nearest neighbor analysis. American Antiquity, v. 39, n. 1, 1974. p. 16-34.

WHITACKER, A. M. Reestruturação Urbana e Centralidade em São José do Rio Preto-SP. 2003. 238 f. Tese (Doutorado em Geografia) Universidade Estadual Paulista, Faculdade de Ciências e Tecnologia, Presidente Prudente, 2003.

ZHANG.T.; SUN. B.; LI. W. The economic performance of urban structure: From the perspective of Polycentricity and Monocentricity. Cities, n. 68, 2017. p. 18-24. DOI: 10.1016/j.cities.2017.05.002 


\section{Biografia do autor principal}

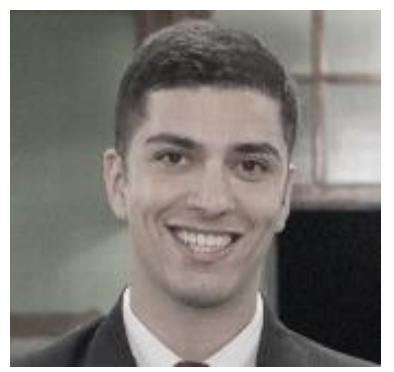

Caio Flávio Martinez Fontoura Júnior nasceu em 1993 no município de Piraí, RJ. Possui graduação em Engenharia de Agrimensura e Cartográfica pela Universidade Federal Rural do Rio de Janeiro (UFRRJ) e mestrado em Ciências Cartográficas pela Universidade Estadual Paulista (Unesp). Atualmente é doutorando no Programa de Pós-Graduação em Ciências Cartográficas da Universidade Estadual Paulista (Unesp/FCT-Presidente Prudente). outros distribuam, remixem, adaptem e criem a partir do seu trabalho, mesmo para fins comerciais, desde que lhe atribuam o devido crédito pela criação original. 